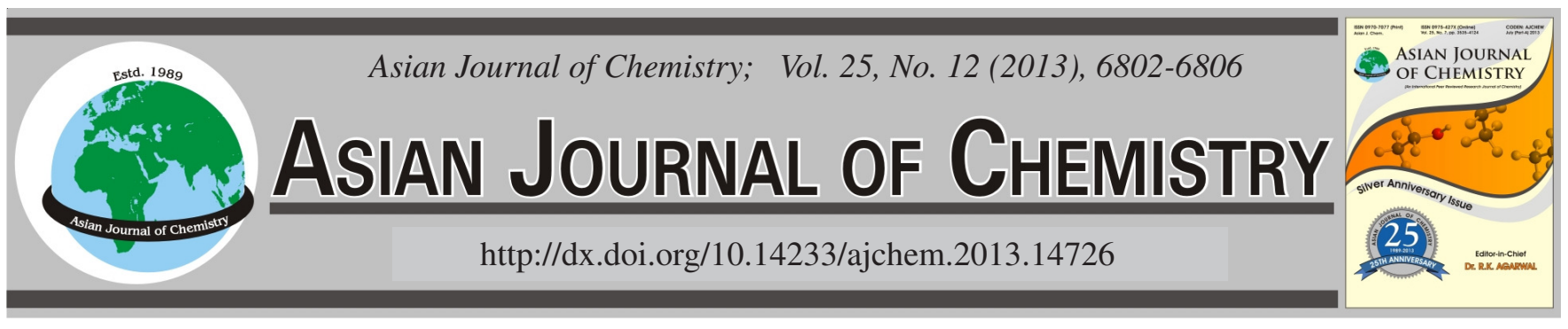

\title{
Kinetic Study of Ozone Degradation of 2-Hydroxy-5-nonylbenzaldehyde Oxime in Mine Wastewater
}

\author{
QiURong Zhang ${ }^{1, *}$ and Wenbin Chen $^{2}$
}

${ }^{1}$ Department of Chemical Engineering, Huaihai Institute of Technology, Lianyungang 222005, P.R. China

${ }^{2}$ School of Chemistry Engineering, Huaihai Institute of Technology, Liangyungang 222005, Jiangsu Province, P.R. China

*Corresponding author: Tel: +86 13511569989; E-mail: lygcwb11@163.com

(Received: 20 October 2012;

Accepted: 3 June 2013)

AJC-13575

\begin{abstract}
In this paper, we studied the ozone degradation characteristics of 2-hydroxy-5-nonylbenzaldehyde oxime in water, we also investigated the influence of various factors on ozone degradation of 2-hydroxy-5-nonylbenzaldehyde oxime. The results show that $\mathrm{pH}$, the initial concentration of 2-hydroxy-5-nonylbenzaldehyde oxime and ozone dosage have greater impact on the oxidation of 2-hydroxy-5nonylbenzaldehyde. The mechanism and kinetics of ozone treatment of 2-hydroxy-5-nonylbenzaldehyde oxime were discussed. The treatment rate of 2-hydroxy-5-nonylbenzaldehyde oxime in actual mine waste water reached $93 \%$, with significant treatment effect.

Key Words: 2-hydroxy-5-nonylbenzaldehyde oxime, Ozone degradation.
\end{abstract}

\section{INTRODUCTION}

Mining organic pollutants in pharmaceutical and its complex pollutants have caused many environmental pollution problems. The pharmaceuticals used in mines, according to different functions, can be divided into collecting agents, inhibitor, foaming agents, activating agents, dispersing agents, flocculant, $\mathrm{pH}$ adjusting agents and many other types ${ }^{1,2}$. Among them, collecting agents, inhibitor and foaming agents are the most important classes of pharmaceutical. China's flotation reagent used in the non-ferrous metals mining is variety and large amount, yellow drugs and black drugs are the main collecting agents and they are the organic pollutants containing sulfur or phosphorus. Foaming agents with pine oil-based, pinitol is turpentine oil as raw materials terpenols class of organic compounds, the substance is extremely difficult to biological degradation and caused the cumulative long-term environmental pollution ${ }^{3}$.

In 1985, only the United States' use chemical agents had mine up $700000 \mathrm{t}$ per year, according to this figure, we can calculate the amount of chemicals in mines in China should be 1 million $t$ per year or more. The dosage of pesticides which has caused environmental research attention has reached 300 000 t per year, compared to this, the dosage of mine chemical agents is 3 times the amount of pesticides. Only southern Jiangxi, the amount of the flotation reagent which enters into the environment every day reaches more than 3380 t. Hydro- metallurgy is a new technology, yet many new extractions have no Environmental Risk Assessment. Research suggests that in Lix84, Lix984, Lix98N4, LIX605 and LIX617 copper extraction agents have para-position digital multi-branched nonylphenol, are typical endocrine pollutants (Endocrine Disrupting Chemicals, abbreviated as EDCs), the pollutants are persistent pollutants (POPs $)^{4,5}$. Only copper extraction, for example, per ton of wet copper extraction consume $3 \mathrm{~kg}$ extration, a ten thousand ton hydrometallurgical plant, the extraction solvent loss was $3 \times 10^{4} \mathrm{~kg} /$ years. They are not easily degradable, insoluble in water and toxic, so once into the mine environment, the effects are long-term. The LIX605 is the compound of 2-hydroxy-5-nonylbenzaldehyde oxime added nonylphenol and the LIX617 is the mixture of the 2-hydroxy5-nonylbenzaldehyde oxime added three decanol ${ }^{6}$. But there was no report about the treatment of 2-hydroxy-5-nonylbenzaldehyde oxime.

Ozone and combinations have attracted much attention because of its strong oxidizing process, no secondary pollution and gradually become a research hotspot. Kremer ${ }^{7}$, in the experiments of ozonation degradation of nitro-chlorobenzene found that in the process of the direct reaction of nitro-chlorobenzene, $m$-nitro-chlorobenzene, $o$-nitro chlorobenzene and ozone molecules, the removal rate of CNBs in the process of ozone oxidation reached $99 \%$, while TOC removal efficiency is onlyabout $45 \%$. Stockinger ${ }^{8}$ and his partners used ozone to treat integrated waste water which containing 4-chloro- 
nitrobenzene, 1,3-dinitrobenzene, 1,2-dichloro-nitrobenzene, chlorobenzene and nitrobenzene and other 10 kinds of aromatic pollutants, after the treatment of ozone $450 \mathrm{~min}$, the aromatic hydrocarbon removal rate was $99.9 \%$, TOC removal rate was $37.6 \%$, water treated by ozone oxidation, biodegradability significantly increased; Pan Xun and Wen-Rong ${ }^{9}$ conducted experimental study on the citric acid wastewater with ozone, found in ozone consumption of $30 \mathrm{mg} / \mathrm{L}$, reaction $5 \mathrm{~min}$, decolorization of the wastewater was $73.3 \%$, while $\mathrm{COD}_{\mathrm{Cr}}$ also declined. Numerous studies show that the 2-hydroxy-5nonylbenzaldehyde oxime is difficult to decompose under natural conditions and easy to bioaccumulate in the environment, which has been shown to have biological toxicity. This paper mainly studies the ozonation degradation characteristics of 2-hydroxy-5-nonylbenzaldehyde oxime in mine wastewater and ozonation TBBP-A of the reaction conditions, mechanisms and kinetics were discussed.

\section{EXPERIMENTAL}

CN62MQXSSP-6890 (Beijing Railway Station West Grand Technology Co., Ltd.); ozone generator SK-CFG-150C (Environmental Protection Technology Co., Ltd Jinan 3 Sport); WFJ-7200 Spectrophotometer (Unico (Shanghai) Instruments Co., Ltd.); Vertical Pressure Steam Sterilizer (Harbin East Union Electronic Technology Co., Ltd.). Calcium chloride solution: $20 \mathrm{mg} / \mathrm{L}$.

In the experiment, we use reagent bottle with volume of $1.5 \mathrm{~L}$ as ozonation reactor, the reaction solution volume is $1 \mathrm{~L}$. Ozone generator provides ozone to the reactor through the sand core aeration placed in the reactor bottom, which makes the ozone dissolved in water rapidly, after a period of time to reach a stable concentration. Exhaust gas through a rubber use KI solution to adsorb. When the ozone concentration in the solution reaches stability, take ozone water from the central sampling port to iodine bottle to be determined.

Chromatographic conditions: Mobile phase were methanol and water, the volume ratio was $85: 15$; column temperature was $40^{\circ} \mathrm{C}$; detection wavelength was $215 \mathrm{~nm}$; the injection volume was $20 \mu \mathrm{L}$; flow rate was $1.0 \mathrm{~mL} / \mathrm{min}$. Experimental results show that the residence time of 2-hydroxy-5-nonylbenzaldehyde oxime standard solution with the concentration of $200 \mathrm{ppm}$ is $c a .4 .0 \mathrm{~min}$.

\section{RESULTS AND DISCUSSION}

Impact of solution pH: In the ozone reaction system, the $\mathrm{pH}$ value of aqueous solution has an important effect on the efficiency of ozone oxidation degradation of organic matters. This is mainly reflected in two aspects: on the one hand, 2-hydroxy-5-nonylbenzaldehyde oxime solubility in aqueous solutions influenced by the $\mathrm{pH}$, under acidic and neutral conditions is basic insoluble, the increase of $\mathrm{pH}$ value helps to the dissolve of 2-hydroxy-5-nonylbenzaldehyde oxime. For most organic compounds, the dissociation state of the ozone oxidation reaction rate is often much higher than the molecular state reaction rate constant ${ }^{10}$. On the other hand, the increase of $\mathrm{pH}$ value will also promote the decomposition of ozone and produce the hydroxyl radical whose oxidation activity is higher than ozone molecules, so as to achieve the purpose of removing the organic matters faster and more completely ${ }^{11}$. Response equations as follows:

$$
\begin{gathered}
\mathrm{O}_{3}+\mathrm{OH}^{-} \rightarrow \mathrm{O}_{2}^{-}+\mathrm{HO}_{2} \\
\mathrm{O}_{3}+\mathrm{O}_{2}^{-} \rightarrow \mathrm{O}_{3}^{-}+\mathrm{O}_{2} \\
\mathrm{O}_{3}+\mathrm{H}^{+} \rightarrow \mathrm{O}_{2}+{ }^{\bullet} \mathrm{OH}
\end{gathered}
$$

The initial concentration of 2-hydroxy-5-nonylbenzaldehyde oxime in wastewater was $50 \mathrm{mg} / \mathrm{L}$, the amount of ozone gas was $\mathrm{Q}=500 \mathrm{~mL} / \mathrm{min}$, reacted for $15 \mathrm{~min}$, under the above conditions, investigated the effects of the ozone on 2-hydroxy5-nonylbenzaldehyde oxime oxidation effect at different $\mathrm{pH}$ values, with the $\mathrm{pH}$ increased, the removal rate of 2-hydroxy5 -nonylbenzaldehyde oxime increased. When the $\mathrm{pH}$ rose to 9.2, the removal rate of 2-hydroxy-5-nonylbenzaldehyde oxime reached the maximum $(95.6 \%)$. One reason is that in alkaline conditions, the hydroxide as catalyst, resulting in the ozone produced stronger hydroxyl radical oxidation, accelerated effective decomposition of 2-hydroxy-5-nonylbenzaldehyde oxime and on the other hand because TBBP-A has low solubility in water at the lower $\mathrm{pH}$, prevented ozone effective oxidation of 2-hydroxy-5-nonylbenzaldehyde oxime, while at higher $\mathrm{pH}$ conditions $(\mathrm{pH}>7), 2$-hydroxy-5-nonylbenzaldehyde oxime essential to fully dissolve, reducing the system mass transfer resistance, was conducive to ozone oxidation on the 2-hydroxy-5-nonylbenzaldehyde oxime.

As ozone always exist these two reactions above in the process of the reaction, namely oxidation of 2-hydroxy-5nonylbenzaldehyde oxime and ozone self-decomposition, hydroxyl ions as a good promoter of ozone self-decomposition, when the concentration of hydrogen ions is very low, the decomposition rate of ozone relative to the ozone oxidation of 2-hydroxy-5-nonylbenzaldehyde oxime is negligible, but if the concentration of hydrogen ions is high, the ozone decomposition process itself can not be ignored. A lot of research literature related to ozone oxidation of organic matters in the study of the solution $\mathrm{pH}$ value effective factors, make the optimum limit of the studied $\mathrm{pH}$ value to $8-9$.

Influence of the initial concentration of 2-hydroxy-5nonylbenzaldehyde oxime: Under the condition that the $\mathrm{pH}$ was 9.2 and the ozone air flow rate was $500 \mathrm{~mL} / \mathrm{min}$, conducted ozonation experiments on the 2-hydroxy-5-nonylbenzaldehyde oxime solution whose initial concentration were $15,30,50$, 80 and $100 \mathrm{mg} / \mathrm{L}$. Under the same conditions, degradation rate of 2-hydroxy-5-nonylbenzaldehyde oxime with different initial concentrations was different and 2-hydroxy-5nonylbenzaldehyde oxime with low concentration degraded faster. When the initial concentration of TBBP-A was $15 \mathrm{mg}$ / $\mathrm{L}$, reacted to $10 \mathrm{~min}, 2$-hydroxy-5-nonylbenzaldehyde oxime had been completely removed, but from the point of absolute amount of degradation, the higher initial concentration of 2-hydroxy-5-nonylbenzaldehyde oxime, the absolute degradation of capacity also increased. This is because when the initial concentration is high, the concentration of intermediate products of ozone oxidation of 2-hydroxy-5-nonylbenzaldehyde oxime is higher, while many of the intermediate products are oxidized more easily, they competed for dissolved ozone with 2-hydroxy-5-nonylbenzaldehyde oxime, leading 
to the decrease rate of the concentration of 2-hydroxy-5nonylbenzaldehyde oxime slowed down properly, but made the intermediate consumption of ozone increase, so the removal rate of 2-hydroxy-5-nonylbenzaldehyde oxime decreased. Therefore, when the initial concentration of 2-hydroxy5-nonylbenzaldehyde oxime was higher, the removal rate was lower, but the absolute degradation declined.

Influence of ozone dosage on the degradation: Under the conditions that the initial concentration of the 2-hydroxy5 -nonylbenzaldehyde oxime solution was $50 \mathrm{mg} / \mathrm{L}, \mathrm{pH}$ was 9.2 , the oxygen flow rate was $500 \mathrm{~mL} / \mathrm{min}$, after reacting 10 min, sample testing. The effect on the degradation and ozone utilization of 2-hydroxy-5-nonylbenzaldehyde oxime were investigated when the ozone dosage were 15, 30, 50, 70 and $90 \mathrm{mg} / \mathrm{h}$.

With the increase of ozone dosage, the removal rate of 2-hydroxy-5-nonylbenzaldehyde oxime increased. This is because with the increase of ozone dosage, the concentration of ${ }^{\bullet} \mathrm{OH}$ produced under unit time per unit volume increased, which accelerates the oxidation of the TBBP-A. When the ozone dosage was $70 \mathrm{mg} / \mathrm{h}, 2$-hydroxy-5-nonylbenzaldehyde oxime basically removed. But with the increase of ozone dosage, ozone usage efficiency decreased. This shows that the increase in dosage, resulting in some ozone is too late to participate in response and discharge into the system directly. Therefore, considering the treatment efficiency and operating costs, this study has selected the best ozone dosage of $50 \mathrm{mg} / \mathrm{h}$.

Kinetics and mechanism of degradation of 2-hydroxy-5nonylbenzaldehyde oxime by ozonation

Analysis and constitute the kinetics mode: From the ozone oxidation mechanism one can know that at the time of ozone reacting with organic matter, there may be exist a direct effect of ozone molecules and the indirect effects of hydroxyl radical. The ozone oxidation of organic matter generally considered as the second order of reaction, i.e., the reaction of pollutant $\mathrm{M}$ with oxidant ozone or ${ }^{\bullet} \mathrm{OH}$ oxidant take up each level, so the ozone reaction rate can be expressed as the sum of directly and indirectly reaction rate, then dynamic model of ozonation of 2-hydroxy-5-nonylbenzaldehyde oxime (HNBDEO) can be expressed as follows:

$$
\begin{aligned}
\frac{\mathrm{d}[\mathrm{HNBDEO}]}{\mathrm{dt}} & =\mathrm{k}_{\mathrm{O}_{3}}[\mathrm{HNBDEO}]\left[\mathrm{O}_{3}\right] \\
& +\mathrm{k}_{\bullet_{\mathrm{OH}}}[\mathrm{HNBDEO}]\left[{ }^{\bullet} \mathrm{OH}\right]
\end{aligned}
$$

In the formula, $\mathrm{K}_{\mathrm{O}_{3}}, \mathrm{~K}_{\mathrm{OH}}$, respectively represent the reaction rate constant of ozone molecules react with 2-hydroxy-5nonylbenzaldehyde oxime and the reaction rate constant of hydroxyl radical react with 2-hydroxy-5-nonylbenzaldehyde oxime.

\section{Calculation of the reaction rate constants}

Function of ozone molecules: If there is only the direct oxidation of ozone molecules, then eqn. 1 can be written as:

$$
\frac{\mathrm{d}[\mathrm{HNBDEO}]}{\mathrm{dt}}=\mathrm{k}_{\mathrm{O}_{3}}[\mathrm{HNBDEO}]\left[\mathrm{O}_{3}\right]
$$

It is still difficult to obtain the reaction rate constant from eqn. 2 and control the ozone concentration of the reaction system to remain unchanged is needed, i.e., keep $\left[\mathrm{O}_{3}\right]$ constant, then eqn. 2 can be changed into:

$$
\left.\frac{\ln \left([\mathrm{HNBDEO}]_{0}\right.}{[\mathrm{HNBDEO}]}\right)=\mathrm{k}_{\mathrm{O}_{3}}\left[\mathrm{O}_{3}\right] \mathrm{t}
$$

Make $\mathrm{k}_{\mathrm{O}_{3}}\left[\mathrm{O}_{3}\right]=\mathrm{k}_{1}^{\prime}$, using the concentration change of 2-hydroxy-5-nonylbenzaldehyde oxime during different ozonation time to obtain $\mathrm{k}_{1}^{\prime}$, thus $\mathrm{k}_{\mathrm{O}_{3}}$ is available.

To eliminate the role of hydroxyl radicals, adjust the $\mathrm{pH}$ of reaction solution to 2 , then add a moderate free radical scavengers, because tert-butyl alcohol (TBA) and the ozone has a very low reaction rate $\left(\mathrm{k}_{\mathrm{O}_{3}}=3 \times 10^{-3} \mathrm{~L} \mathrm{~mol}^{-1} \mathrm{~s}^{-1}\right)$, but with a higher reaction rate of hydroxyl radical $\left(\mathrm{k}^{\bullet} \mathrm{OH}=6 \times\right.$ $\left.10^{8} \mathrm{~L} \mathrm{~mol}^{-1} \mathrm{~s}^{-1}\right)$, can effectively quench free radicals ${ }^{56}$, so try to use TBA as the free radical scavengers. The dosage concentration of tert-butanol radical quencher should be far greater than the concentration of TBBP-A, in the experiment, we tested the effect of TBA on the ozone reaction rate constant of 2-hydroxy-5-nonylbenzaldehyde oxime at the range of 0-0.01 $\mathrm{mol} / \mathrm{L}$. The experiment conducted under the condition that the $\mathrm{pH}$ was 2 and the liquid ozone concentration was $5 \mathrm{mg} / \mathrm{L}$, the results (Fig. 1).

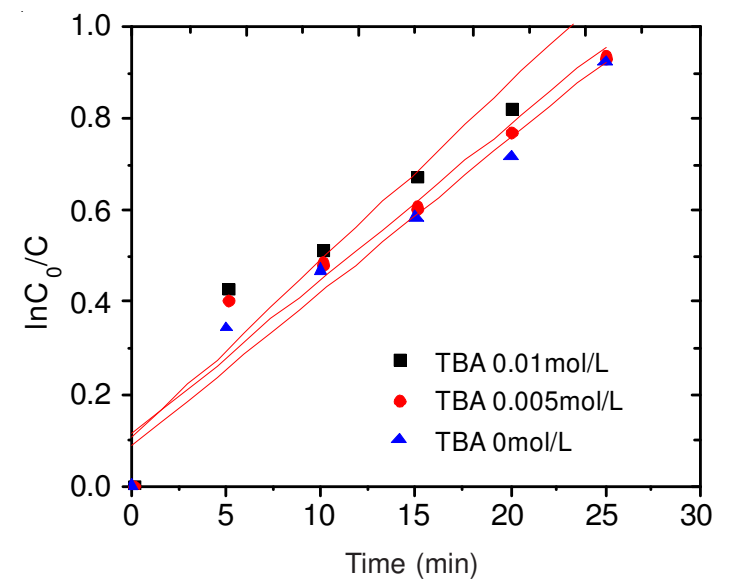

Fig. 1. Effect of TBA on ozonation rate of 2-hydroxy-5-nonylbenzaldehyde oxime

The linear regression of tert-butanol concentrations were $0,0.005$ and $0.01 \mathrm{~mol} / \mathrm{L}$ of $\ln \left([\mathrm{HNBDEO}]_{0} /[\mathrm{HNBDEO}]\right)$ and the reaction time $t$, Table- 1 lists the linear regression equation and reaction rate constant $\mathrm{k}_{\mathrm{O}_{3}}$. It can be seen from the results that as the concentration of tert-butyl alcohol in solution increases, the reaction rate constant value increases, that is, tertbutyl alcohol did not play the role of free radical scavengers, or substituted by other more major function, analyze the possible causes, the solubility of 2-hydroxy-5-nonylbenzaldehyde oxime in water is extremely low when the $\mathrm{pH}$ is 2 , but soluble in organic solvents such as ethanol, the join of tert-butanol promoted the dissolution of 2-hydroxy-5-nonylbenzaldehyde oxime in water, increased the contact oxidation rate of ozone reacted with 2-hydroxy-5-nonylbenzaldehyde oxime, the function played the dominant role, so the tert-butanol is not suitable as free radical scavengers in this response system.

With the fact that the reaction rate of sodium carbonate and sodium bicarbonate with the hydroxyl radical is much faster than the average organic matter, it is also a good free radical 
TABLE-1

REACTION RATES IN DIFFERENT CONCENTRATION OF TBA

\begin{tabular}{ccccc}
\hline tert-Butanol concentration $(\mathrm{mol} / \mathrm{L})$ & Linear regression equation & Correlation coefficient $(\mathrm{R})$ & $\mathrm{k}_{1}^{\prime}\left(\mathrm{min}^{-1}\right)$ & $\mathrm{k}_{\mathrm{O}_{3}}[\mathrm{~L} /(\mathrm{mol} \mathrm{S})]$ \\
\hline 0 & $\mathrm{Y}=0.0385 \mathrm{x}+0.0858$ & 0.9830 & 0.0346 & 5.63 \\
0.005 & $\mathrm{Y}=0.0376 \mathrm{x}+0.1226$ & 0.9805 & 0.0345 & 5.65 \\
0.01 & $\mathrm{Y}=0.0395+0.1114$ & 0.9786 & 0.0346 & 6.37 \\
\hline
\end{tabular}

scavenger. In the experiment, we investigated the reaction rate of ozone and 2-hydroxy-5-nonylbenzaldehyde oxime under the conditions that without sodium carbonate and sodium carbonate concentration of $0.2 \mathrm{~g} / \mathrm{L}$ when the $\mathrm{pH}$ was 2 and liquid concentration was $4 \mathrm{mg} / \mathrm{L}$. Fig. 2 shows the linear regression case of $\ln \left([\mathrm{HNBDEO}]_{0} /[\mathrm{HNBDEO}]\right)$ and the reaction time $t$ under the conditions that sodium carbonate concentration was 0 and $0.2 \mathrm{~g} / \mathrm{L}$, respectively, Table- 2 lists the linear regression equation and response rate constant. It can be seen from the chart that the adding of sodium carbonate has little influence on the reaction rate, that is, in these conditions, the influence of hydroxyl radicals produced by the system itself on the 2-hydroxy-5-nonylbenzaldehyde oxime can be neglected, at the same time Lucas and others' study show that when the $\mathrm{pH}$ value is lower than 5.5, you can ignore the step that ozone changes into hydroxyl radicals, the conclusions consistant the experimental results.

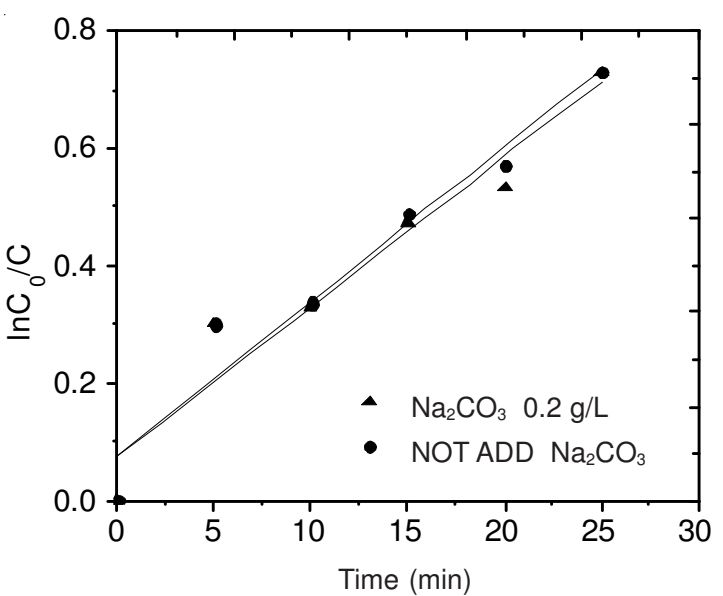

Fig. 2. Effect of $\mathrm{Na}_{2} \mathrm{CO}_{3}$ on ozonation of 2-hydroxy-5-nonylbenzaldehyde oxime

\begin{tabular}{ccccc}
\multicolumn{5}{c}{ TABLE-2 } \\
\multicolumn{5}{c}{$\begin{array}{c}\text { REACTION RATES IN DIFFERENT } \\
\text { CONCENTRATION OF Na } \mathrm{CO}_{3}\end{array}$} \\
\hline $\begin{array}{c}\text { Sodium } \\
\text { carbonate } \\
\text { concentration } \\
(\mathrm{g} / \mathrm{L})\end{array}$ & $\begin{array}{c}\text { Linear regression } \\
\text { equation }\end{array}$ & $\begin{array}{c}\text { Correlation } \\
\text { coefficient } \\
(\mathrm{R})\end{array}$ & $\begin{array}{c}\mathrm{k}_{1}^{\prime} \\
\left(\mathrm{min}^{-1}\right)\end{array}$ & $\begin{array}{c}\mathrm{k}_{\mathrm{O}_{3}} \\
{[\mathrm{~L} /(\mathrm{molS})]}\end{array}$ \\
\hline 0 & $\mathrm{Y}=0.0268 \mathrm{x}+0.0845$ & 0.9785 & 0.0265 & 6.32 \\
0.2 & $\mathrm{Y}=0.0258 \mathrm{x}+0.0825$ & 0.9714 & 0.0258 & 5.98 \\
\hline
\end{tabular}

In summary, the reaction rate constant $\mathrm{k}_{1}{ }_{1}$ of 2-hydroxy5-nonylbenzaldehyde oxime reacted directly with ozone molecules obtained in this study was $0.0264 \mathrm{~min}^{-1}$, after calculated, $\mathrm{k}_{\mathrm{O}_{3}}$ was $6.32 \mathrm{~L} /(\mathrm{mol} \mathrm{s})$.

Function of hydroxyl radicals: Under alkaline conditions, the ozone discomposed rapidly and produced hydroxyl radicals, at this time the effect of ozone molecules can be neglected, the system mainly showed the indirect reaction of
${ }^{\circ} \mathrm{OH}$ and organic matter. Since the reaction rate of ${ }^{\bullet} \mathrm{OH}$ reacting with organic matter is quick and non-selective, to determine the reaction rate constant of ${ }^{\circ} \mathrm{OH}$ with the target substance directly is very difficult, so in this study, we use the method of competitive dynamics to determine the reaction rate constant of targets and ${ }^{\circ} \mathrm{OH}$. In this study choose phenol as the competitive reference material, the reaction rate constant of literature value of this material and the ${ }^{\circ} \mathrm{OH}$ is $1.4 \times 10^{9} \mathrm{~L} /(\mathrm{mol} \mathrm{s})$.

Add $100 \mathrm{mg} / \mathrm{L}$ of phenol into the reaction solution as a competitive thing, adjust system $\mathrm{pH}$ to 10 and then pass into the ozone gas with constant flow and known concentration, after a certain respective reaction time, sampling, the reaction was terminated with $\mathrm{Na}_{2} \mathrm{SO}_{3}$ and then determine the concentration of reference object and targets. There exist two or more kinds of material react with ${ }^{\circ} \mathrm{OH}$ in the reaction-based system:

$$
\mathrm{k}_{\bullet \mathrm{OH}}=\frac{\ln \left([\mathrm{HNBDEO}]_{0} /[\text { HNBDEO }]\right)}{\ln \left([\text { phenol }]_{0} /[\text { phenol }]\right)} \mathrm{k}_{\bullet \mathrm{OH}}^{\prime}
$$

In the formula: [HNBDEO $]_{0}$, [phenol $]_{0}$ and [HNBDEO], [phenol] were the concentration of HNBDEO, reference material phenol before and after reaction; $\left[{ }^{\circ} \mathrm{OH}\right]$ is the concentration of the radical; $\mathrm{k}^{\bullet} \mathrm{OH}, \mathrm{k}^{\cdot}{ }_{\mathrm{OH}}$ are the reaction rate constant of, material HNBDEO, phenol and ${ }^{\circ} \mathrm{OH}$, respectively, $\mathrm{L} /(\mathrm{mol} \mathrm{s})$.

Make $\mathrm{k} \cdot{ }_{\mathrm{OH}}\left[{ }^{\bullet} \mathrm{OH}\right]=\mathrm{k}_{2}^{\prime}, \mathrm{k}^{\prime} \cdot{ }_{\mathrm{OH}}\left[{ }^{\bullet} \mathrm{OH}\right]=\mathrm{k}_{2}^{\prime \prime}$, use the concentration change of HNBDEO and phenol at different ozonation time can obtain the values of $\mathrm{k}_{2}^{\prime}, \mathrm{k}_{2}{ }_{2}$ are 0.1324 , 0.0426 , that is, the reaction rate of hydroxyl radical and HNBDEO is much faster than the reaction with phenol.

Because it is difficult to determine the hydroxyl radical accurately, so we just need to obtain the ratio of $1 n$ ([HNBDEO $]_{0} /[$ HNBDEO] $)$ and $\ln \left([\text { phenol }]_{0} /[\right.$ phenol $\left.]\right)$. The measured value of $\ln \left([\mathrm{HNBDEO}]_{0} /[\mathrm{HNBDEO}]\right) / \ln \left([\mathrm{phenol}]_{0} /\right.$ [phenol]) was 3.512, calculated reaction rate constant $\mathrm{k}{ }_{\mathrm{OH}} \mathrm{of}$ HNBDEO and hydroxyl radicals was $5.12 \times 10^{9} \mathrm{~L} /(\mathrm{mol} \mathrm{s})$. Many studies show that the magnitude of the reaction rate constants of hydroxyl radical reacts with organic compounds are $c a .9$, consistent with the experimental results.

In summary, the direct reaction rate constant of HNBDEO and ozone molecules is $6.32 \mathrm{~L} /(\mathrm{mol} \mathrm{s})$ and the reaction rate constant of hydroxyl radical is $5.12 \times 10^{9} \mathrm{~L} /(\mathrm{mol} \mathrm{s})$, from the reaction rate constant point of view, the ozonation process of 2-hydroxy-5-nonylbenzaldehyde oxime is mainly reacts with free radical reactions.

\section{Dynamic model between time and adsorption capacity}

Quasi-second order dynamic model: Table-3 showed that at different temperatures and at the same time, the value of reaction rate constant $\mathrm{k}_{2}$ is not the same, the size of $\mathrm{k}_{2}$ shows the size of the reaction rate, Fig. 2 suggested that the reaction rate of $37^{\circ} \mathrm{C}$ is greater than $25^{\circ} \mathrm{C}$ and the reaction rate of $25^{\circ} \mathrm{C}$ is greater than the response rate of $20^{\circ} \mathrm{C}$. 
TABLE-3

QUASI-SECOND ORDER DYNAMIC PARAMETERS

\begin{tabular}{cccccc}
\hline Temperature $\left({ }^{\circ} \mathrm{C}\right)$ & Regression equation & $\mathrm{R}$ & $\mathrm{k}_{2}(\mathrm{~g} /(\mathrm{mg} \mathrm{min}))$ & $\mathrm{q}_{\mathrm{e}}(\mathrm{mg} / \mathrm{g})$ & $\mathrm{k}_{2} \mathrm{q}_{\mathrm{e}}{ }^{2}(\mathrm{mg} /(\mathrm{g} \mathrm{min}))$ \\
\hline 20 & $\mathrm{y}=0.07573+0.12129 \mathrm{x}$ & 0.9998 & 0.1943 & 8.2447 & 13.20756 \\
25 & $\mathrm{y}=0.06529+0.11210 \mathrm{x}$ & 0.9999 & 0.2017 & 8.9210 & 16.05214 \\
37 & $\mathrm{y}=0.06317+0.10605 \mathrm{x}$ & 0.9998 & 0.2076 & 8.9430 & 16.60328 \\
\hline
\end{tabular}

Quasi-first dynamic model: Table-4 showed that the correlation coefficient $\mathrm{R}$ of three fitting equations values above 0.9 , at different temperatures and at the same time, the value of the reaction rate constant $\mathrm{k}_{1}$ is not the same, the size of $\mathrm{k}_{1}$ value shows the reaction rate size, it can be seen from the figures that $\mathrm{k}_{1}$ increases with the increasing temperature, the reaction rate of $37^{\circ} \mathrm{C}$ is greater than the response rate of $25^{\circ} \mathrm{C}$ and reaction rate of $20^{\circ} \mathrm{C}$, at this point, the results are consensus with the results of quasi-second order kinetic model.

TABLE-4

QUASI-FIRST DYNAMIC MODEL FITTING PARAMETERS

\begin{tabular}{ccccc}
\hline $\begin{array}{c}\text { Temp. } \\
\left({ }^{\circ} \mathrm{C}\right)\end{array}$ & Regression equation & $\mathrm{R}$ & $\begin{array}{c}\mathrm{k}_{1} \\
\left(\mathrm{~min}^{-1}\right)\end{array}$ & $\begin{array}{c}\mathrm{q}_{\mathrm{e}} \\
(\mathrm{mg} / \mathrm{g})\end{array}$ \\
\hline 20 & $\mathrm{y}=-2.04248-0.03157 \mathrm{x}$ & 0.90942 & 0.07271 & 8.2447 \\
25 & $\mathrm{y}=-2.13122-0.03231 \mathrm{x}$ & 0.90745 & 0.07439 & 8.9210 \\
37 & $\mathrm{y}=-2.08405-0.03248 \mathrm{x}$ & 0.91066 & 0.07480 & 8.9430 \\
\hline
\end{tabular}

TABLE-5
ACTUAL TREATMENT OF WASTE WATER (OZONE
CONCENTRATION 50 mg/L, REACTION TIME 0.5 h)

\section{Conclution}

In different 2-hydroxy-5-nonylbenzaldehyde oxime initial concentration, different $\mathrm{pH}$ values and different dosage of ozone, the ozone degradation of the 2-hydroxy-5-nonylbenzaldehyde oxime also consistent with the standard second-order reaction kinetics. The apparent reaction rate constant decreased with the increasing of the initial concentration of 2-hydroxy5-nonylbenzaldehyde oxime; and increased with the increase of ozone dosage. In a certain range, the reaction rate and the
$\mathrm{pH}$ of solution shows a positive relevance, but when $\mathrm{pH}$ is greater than 9, the reaction rate decreased; i.e., the apparent reaction rate constants is negatively correlated with the initial concentration of 2-hydroxy-5-nonylbenzaldehyde oxime and is positive correlated with the ozone dosage and solution $\mathrm{pH}$ values. Tert-butyl alcohol has a function of solubilization to 2-hydroxy-5-nonylbenzaldehyde oxime, so it is unsuited to act as free radical scavenger in this response system. Use sodium carbonate to eliminate the effect of free radicals, compared with the two conditions: without sodium carbonate and with $0.2 \mathrm{~g} / \mathrm{L}$ sodium carbonate. The experimental results show that under the experimental conditions ( $\mathrm{pH} 2.0$ ), the existence of hydroxyl free radical can be ignored, so we can test the direct reaction rate constant of TBBP-A reacted with ozone was $6.32 \mathrm{~L} /(\mathrm{mol} \mathrm{s})$. Ozone treatment rate of 2-hydroxy5 -nonylbenzaldehyde oxime in actual wastewater can reach $93 \%$.

\section{REFERENCES}

1. Q.F. Song and G.A. Yang, J. Metallic Ore Dressing Abroad, 37, 39 (2000).

2. X.-Y. Wang, D.-S. Ding, P. Xiang and J.Z. Liu, J. Hunan Nonferrous Met., 16, 9 (2000).

3. L.M. Luo, G.B. Huang, G. Li and Z.Y. Shao, J. Wuhan Institute Chem. Technol., 26, 23 (2004)

4. W. Yao and H.L. Luan, Mining \& Metallurgy, 10, 82 (2001).

5. C.Y. Jin, Y.F. Zheng and X.G. Huang, J. Environ. Protection Sci., 28, 30 (2002).

6. S.H. Pei, R.L. Xie, M. Jin, F. Gao and D. Qin, J. Contemporary Chem. Ind., 38, 78 (2009).

7. M.L. Kremer, Int. J. Chem. Kinet., 17, 1299 (1985).

8. H. Stockinger, E. Heinzle and O.M. Kut, Environ. Sci. Technol., 29, 2016 (1995).

9. X. Pan and W.R. Hu, J. Ind. Water Treat., 27, 31 (2007)..

10. J. Hoigne and H. Bader, Water Res., 17, 173, 185 (1983).

11. J. Hoigne, in eds: R.G. Rice and A. Netzer, Mechanisms, Rates and Selectivities of Oxidation of Organic Compounds Initiated by Ozonation of Water, In Ozone Technology and Its Practical Applications, Ann Arbor Science, Vol. 1, pp. 341-379 (1982). 